\title{
A palavra cantada
}

Luciana Barongeno ${ }^{1}$

\begin{abstract}
MATOS, Cláudia Neiva de; TRAVASSOS, Elizabeth e MEDEIROS, Fernanda Teixeira de (Orgs.). Palavra cantada: ensaios sobre poesia, música e voz. Rio de Janeiro: 7 letras, 2008. 346p.
\end{abstract}

O livro Palavra cantada: ensaios sobre poesia, música e voz reúne os trabalhos apresentados no II Encontro de Estudos da Palavra Cantada, realizado em maio de 2006 no Fórum de Ciência e Cultura da Universidade Federal do Rio de Janeiro. Coordenado por Cláudia Neiva de Matos, Elizabeth Travassos e Fernanda Teixeira de Medeiros, o evento deu seguimento ao I Encontro, conduzido pelas mesmas organizadoras na Universidade Federal Fluminense, em setembro de 2000, e cujos textos estão publicados no livro Ao encontro da palavra cantada: poesia, música e voz (Rio de Janeiro: 7 Letras, 2001).

O II Encontro fomentou a integração de especialistas de diversas áreas do conhecimento, provenientes de diferentes instituições acadêmicas brasileiras e internacionais, na tentativa de refletir sobre as dimensões verbal, musical e vocal da palavra cantada, considerada em seus aspectos estéticos, semânticos e histórico-culturais. O livro apresenta vinte ensaios de pesquisadores das áreas de Musicologia, Etnomusicologia, Literatura, Lingüística, Semiótica, Antropologia, História, Filosofia, Comunicação, Teatro e Artes Cênicas e conta com a contribuição de um especialista em técnica vocal e dois compositores e intérpretes da música popular.

O "Índice" anuncia a amplitude com que o tema é abordado e, de algum modo, reflete a dificuldade habitual em se estabelecer limites precisos de investigação para os objetos abrangidos pela palavra cantada. Não é raro observamos que, no discurso acadêmico, a canção pode parecer um fenômeno completamente distinto quando analisada segundo parâmetros específicos de uma ou outra área do conhecimento. As interfaces entre texto, música e voz podem se localizar em diferentes níveis de análise e variar conforme o objeto, no entanto, essa

1 Doutoranda do Curso de Pós-Graduação em Musicologia da Escola de Comunicações e Artes da Universidade de São Paulo. São Paulo, Brasil.

E-mail: lubarongeno@terra.com.br 
heterogeneidade, que caracteriza a reflexão sobre a palavra cantada e possibilita a especialização, pode, paradoxalmente, comprometer a compreensão integrada do tema, na medida em que disciplinas diferentes, inúmeras vezes, demonstram desacordos recíprocos. Este é um traço evidente em alguns ensaios do livro.

A distribuição dos capítulos em ordem alfabética parece promover essa sobreposição de abordagens. Todavia, o texto de abertura de Ruth Finnegan, que retomarei a seguir, destaca-se por ser ponto de convergência para os demais ensaios, na medida em que ilumina caminhos para uma compreensão integrada da canção. Na "Introdução", as organizadoras apresentam cinco categorias de análise. A primeira discute aspectos teóricos e metodológicos que podem orientar o estudo da canção. Cláudia Neiva de Matos mapeia a história das relações entre a linguagem poética e a linguagem musical segundo a análise crítica da modernidade. Tomando como referência estudos literários, filosóficos e musicais, entre outros, organiza o pensamento em torno de dois eixos de reflexão: o que premia as analogias intrínsecas entre música e poesia e o que prevê a interação de texto e música no canto. Pedro Marques atrela poesia e música a partir da análise comparativa entre o pensamento estético de Stéphane Mallarmé e o de Mário de Andrade. Monclar Valverde associa o poder de comunicação da canção à estrutura narrativa da tonalidade e à origem musical das línguas. Tereza Virgínia de Almeida reflete sobre os desafios impostos pela canção popular como objeto de estudos literários.

A segunda categoria destaca a canção popular mediatizada, tratada do ponto de vista histórico, analítico, composicional e performático. Heloísa de Araújo Duarte Valente parte do conceito de "movência", de Paul Zumthor, para estudar o tango brasileiro. Liv Sovik analisa a "linha evolutiva" da canção brasileira, resgatando, na figura de Angela Maria, aspectos da música popular perdidos com o advento da bossa nova. Luiz Tatit e Ivã Carlos Lopes descrevem de que modo a organização dos planos da expressão e do conteúdo garantem o resultado estético homogêneo da canção Eu sei que vou te amar, de Tom Jobim e Vinícius de Moraes. Henrique Cazes relata as dificuldades impostas à colocação de letra no choro, gênero originalmente instrumental. $\mathrm{O}$ depoimento de Adriana Calcanhoto, que nasce das perguntas formuladas pelas organizadoras e pelo público, aborda questões relacionadas à composição em parceria, musicalização de textos, técnica vocal e canto. Felipe Abreu explica as possibilidades de atuação do preparador vocal nas diferentes fases do processo de gravação de um disco em estúdio, na apresentação ao vivo e na interlocução com o artista. 
A canção erudita aparece na análise de dois documentos musicais. Carlos Alberto Figueiredo propõe um roteiro baseado em regras prosódicas renascentistas para estabelecer o texto musical no Ofício dos Defuntos a 8 vozes, de José Maurício Nunes Garcia. Gisele Pires de Oliveira e Lúcia Barrenechea formulam uma abordagem multidisciplinar para a análise de "Cantiga", canção que abre o ciclo Quatro líricas (1938) de Francisco Mignone com texto de Manuel Bandeira. Baseada na relação entre texto e música, nos conceitos de persona e modo de direcionamento, a análise fornece ainda subsídios para a interpretação.

As reflexões da quarta categoria pertencem ao domínio da oralidade. Carlos Sandroni questiona em que medida os cantos levantados no xangô do Recife são palavras ou sons vocalizados. Fernando José Carvalhaes Duarte investiga analogias entre o aboio brasileiro e o jubilus medieval, utilizando a noção de "antropologia do gesto" de Marcel Jousse. Em jornais e partituras originais, José Geraldo Vinci de Moraes identifica peculiaridades das "modinhas paulistas" que revelam aspectos do cotidiano e da cultura urbana nas décadas de 20 e 30. Maria Ignez Cruz Mello estuda os cantos femininos dos índios Wauja no ritual de iamurikuma. Marcus Vinícius Carvalho Garcia e Elen Döppenschmitt comparam a performance do cantor e compositor Adão Xalebaradão no documentário Somos todos filhos da terra e no CD Escolástica e discutem o papel da indústria cultural no registro de tradições orais populares. Martha Tupinambá de Ulhôa analisa versões gravadas da modinha Perdão Emília! e discute aspectos da transmissão oral e aural na canção popular urbana. Paula Cristina Vilas descreve o processo de criação da cena de abertura de Entrama: a história do beija-flor coroado a partir de sua pesquisa de campo no quilombo de Pombal.

Finalmente, a voz aparece nas reflexões de Silvia Adriana Davini, que critica a "abordagem instrumental" corrente na formação de atores, proclamando para a voz a definição de "produção do corpo". Tran Quang Hai discorre sobre aspectos que caracterizam a palavra "falada" e "cantada" na língua vietnamita e Elizabeth Travassos, que retomarei adiante, discute e elabora uma metodologia para o estudo da voz.

O fato de os dois únicos artigos sobre a canção erudita versarem sobre teoria e análise musical, em certa medida, flagra o desvio que a Musicologia sofre a partir do ideal de totalidade que a origina. A Musikwissenschaft do século XIX significa compreender a música em todos os seus aspectos ${ }^{2}$, como um fenômeno múltiplo, cujas dimensões

2 KERMAN, Joseph. Contemplating music: challenges to musicology. Cambridge, Massachusetts: Harvard University Press, 1985. p. 11-12. 
não são alcançadas pela prática e teoria da música ocidental. A noção de música como obra-de-arte autônoma, historicamente, é recente. Ao contrário, a origem e desenvolvimento da música se deram através de “obras abertas", organizadas em bases biológicas, culturais e sociais ${ }^{3}$. Tomá-la apenas em sua "realidade escrita" (nas palavras de Finnegan) significa recusá-la como experiência estética e humana.

Justamente os ensaios de Ruth Finnegan - $O$ que vem primeiro: o texto, a música ou a performance? - e de Elizabeth Travassos - Um objeto fugidio: voz $e$ "musicologias" - vêm ao encontro dessa questão na medida em que reclamam a necessidade de uma compreensão ampla e integrada dos fenômenos envolvidos na canção. O pensamento das antropólogas coincide em três aspectos: 1) assumem a canção como atividade, 2) questionam as abordagens literárias e musicológicas tradicionais e 3) redimensionam o papel da voz no estudo da palavra cantada.

Para discutir de que modo interagem texto, música e voz, Finnegan desvia o foco de análise e interpretação que toma o modelo da escrita como "realidade" central da canção. Formula sua proposição sobre a "realidade da performance" apoiada em seus estudos, que demonstram que a arte de alguns gêneros verbais não se encontra no texto, mas nos modos com que a voz o transforma. Desse modo, a antropóloga inglesa redimensiona o papel e o significado do texto, deslocando para a voz performática a função de atualizar os elementos que constituem a canção. Na mesma direção, Elizabeth Travassos aponta algumas dificuldades impostas pela própria musicologia ao estudo da voz e do canto; entre elas, a dicotomia de abordagem que dissocia a voz humana da voz cantada. Propõe, então, uma aproximação entre a "cantométrica" de Alan Lomax e as etnografias da fala e da música como instrumentos para compreender e analisar a voz como fenômeno biopsicossocial.

No Brasil, o ideal de totalidade que originalmente conduz a Musicologia é retomado por Mário de Andrade, musicólogo e poeta que deseja compreender o canto e a voz em todas as dimensões. O Primeiro Congresso da Língua Nacional Cantada, realizado em 1937 sob sua tutela, tem, como proposta central, a organização da língua e da linguagem artística dentro de um critério culto, nacional e estético ${ }^{4}$. No

3 CROSS, Ian. Music as biocultural phenomenon. In: AVANZINI, G. et alli (Eds.). The neurosciences and music. Annals of the New York Academy of Sciences, v. 999, p. 109111, 2003. Disponível em: www.mus.cam.ac.uk/ ic108/PDF/IRMCNYAS2003.PDF.

4. ANDRADE, Mário de. A língua padrão. Anais do Primeiro Congresso da Língua Nacional Cantada, p. 9. "Estado de S. Paulo", 1-6-1937. Revista do Arquivo Municipal. Departamento de Cultura. São Paulo, v. XXXVI, p. 342, 1937. 
entanto, um olhar cuidadoso sobre os textos do autor mostra que sua preocupação com o canto e com a voz não se limita ao problema da nacionalização da canção erudita, mas é precedida pelo desejo de compreender os mecanismos envolvidos em sua gênese.

Para organizar o pensamento e criar teorias próprias, Mário de Andrade abre-se para a interdisciplinaridade, esboçada, precocemente, nos artigos que compõem a série Mestres do passado ${ }^{5}$, publicados no “Jornal do Comércio" de São Paulo em 1921. Reportando-se às teorias de Spencer, Darwin, Riemann, Ingenieros, Combarieu e Tolstoi, fundamenta o conceito que norteará os estudos sobre a canção até o ano de sua morte: a palavra cantada e a palavra falada têm origem comum no grito primitivo. Com raízes guardadas na leitura de Herbert Spencer, este conceito servirá de mote para escrever Os compositores e a língua nacional (1937) ${ }^{6}$ e Vida do cantador (1944) ${ }^{7}$. Ao tomar o aboio de Chico Antônio como o início de todos os cantos ${ }^{8}$ e como a manifestação primitiva da canção erudita, Mário de Andrade apresenta um aspecto que fundamenta o seu pensamento sobre a gênese da canção: a organização estética é resultado do equilíbrio entre a realidade do elemento sonoro e a realidade do elemento humano ${ }^{9}$, organizadas em bases biológicas, culturais e sociais.

Musicólogos como A. L. Lloyd, James Porter, R. Katsarova, Ian Cross e Mário de Andrade, entre outros, chamam a atenção para a importância da performance no estudo da canção. Concebidos em condições que agregam som e movimento, interação social, contexto cultural e modulação de estados afetivos, os acalantos, os aboios, os lamentos, as baladas e as músicas de feitiçaria são formas de expressão que podem ajudar a desvendar muitos aspectos da natureza e do propósito da arte.

5 Idem. Mestres do passado. In: BRITO, Mário da Silva. História do modernismo: antecedentes da Semana de Arte moderna. 2. ed. rev. Rio de Janeiro: Civilização Brasileira, 1964, p. 252-309.

6 Idem. Os compositores e a língua nacional, 1937. In: Aspectos da música brasileira. Belo Horizonte e Rio de Janeiro: Villa Rica, 1991, p. 32-94.

7 Idem. Vida do cantador. Edição crítica de Raimunda de Brito Batista. Belo Horizonte e Rio de Janeiro: Villa Rica, 1993.

8 ALMEIDA, Renato. História da Música Brasileira. 2. ed. corr. e aum,. Rio de Janeiro: F. Briguiet, 1942. p. 55 apud ANDRADE, Mário de. Cantos de trabalho. In: TONI, Flávia Camargo e ALVARENGA, Oneyda (Coord.) Dicionário musical brasileiro. Belo Horizonte: Itatiaia; Brasília: Ministério da Cultura; São Paulo: Instituto de Estudos Brasileiros, 1989. p. 108-109. "Chamar o gado, apregoar, bradar no campo, eis provavelmente o início de todos os cantares - afirma A. Graves. As canções de trabalho são, já, talvez, extensões dessas melodias primárias.”

9 ANDRADE, Mário de. Pequena história da música. 6. ed. Belo Horizonte: Itatiaia, p. 113-114. 
Palavra cantada: ensaios sobre poesia, música e voz fornece um panorama dos caminhos a serem trilhados para uma compreensão integrada da canção. Originalmente dirigidos à comunidade acadêmica, os artigos equilibram erudição e rigor de escrita, adquirindo um caráter didático para o aluno de graduação e pós-graduação. A publicação do livro democratiza o conhecimento e convida a pensar sobre a mais humana das expressões.

Recebido em 13 de fevereiro de 2009

Aprovado em 18 de fevereiro de 2009 